\title{
Race is Gendered: How Covarying Phenotypes and Stereotypes Bias Sex Categorization
}

\author{
Kerri L. Johnson \\ University of California, Los Angeles
}

\author{
Jonathan B. Freeman \\ Tufts University
}

\author{
Kristin Pauker \\ Stanford University
}

\begin{abstract}
We argue that race and sex categories are psychologically and phenotypically confounded, affecting social categorizations and their efficiency. Sex categorization of faces was facilitated when the race category shared facial phenotypes or stereotypes with the correct sex category (e.g., Asian women and Black men) but was impaired when the race category shared incompatible phenotypes or stereotypes with the correct sex category (e.g., Asian men and Black women). These patterns were evident in the disambiguation of androgynous faces (Study 1) and the efficiency of judgments (Studies 1, 2, 4, and 5). These patterns emerged due to common facial phenotypes for the categories Black and men (Studies 3 and 5) and due to shared stereotypes among the categories Black and men and the categories Asian and women (Studies 4 and 5). These findings challenge the notion that social categories are perceived independent of one another and show, instead, that race is gendered.
\end{abstract}

Keywords: social categorization, person perception, sex perception, race perception

Social categorization has long been presumed to be an efficient cognitive strategy for managing interpersonal interactions (Allport, 1954; Tajfel, 1969, 1974). Category knowledge, it was argued, elicited a rich array of knowledge structures, or stereotypes, that were recruited to form an impression of others (Allport, 1954; Bargh, 1999; Devine, 1989; Dovidio, Evans, \& Tyler, 1986; Fazio \& Dunton, 1997; Gilbert \& Hixon, 1991; Grant \& Holmes, 1981; Sinclair \& Kunda, 1999; Tajfel, 1969). Not surprisingly, therefore, early empirical work examining social categorization focused heavily on the downstream consequences of social categorization (i.e., stereotyping and prejudice), with less emphasis on the mechanisms of categorization itself.

Increasingly, scholars have sought to understand the mechanisms of social perception in its earliest phases, focusing primarily on how social categorization occurs given minimal visual information. Such work has integrated various approaches from face recognition and stereotyping literatures (Cloutier, Mason, \& Mac-

This article was published Online First August 29, 2011

Kerri L. Johnson, Departments of Communication Studies and Psychology, University of California, Los Angeles; Jonathan B. Freeman, Department of Psychology, Tufts University; Kristin Pauker, Department of Psychology, Stanford University.

This research was supported by National Science Foundation Grant BCS-1052896 awarded to Kerri L. Johnson. We thank members of the Social Communication Lab for assistance with data collection. Portions of these data were presented at the 2009 annual meeting of the Society for Personality and Social Psychology.

Correspondence concerning this article should be addressed to Kerri L. Johnson, Department of Communication Studies, University of California, Los Angeles, 2330 Rolfe Hall, Los Angeles, CA 90095. E-mail: kerri.johnson@ucla.edu rae, 2005; Macrae, Quinn, Mason, \& Quadflieg, 2005; Mason, Cloutier, \& Macrae, 2006; Quinn \& Macrae, 2005). A majority of this research has isolated a single social category while holding other categories constant (e.g., by manipulating race while holding the sex constant). Research investigating social categorization when identities intersect (e.g., when a target is both Asian and male), therefore, remains relatively rare. However, recent attempts to reach a more nuanced understanding of these complexities are noteworthy, and they suggest that the perception of various social categories may be interdependent.

Here we examine the interdependence of social perception when race and sex identities intersect. We propose that although sex and race categories vary orthogonally in reality (or, at most, covary to a small but unknown degree), the perception of these categories is intertwined. Specifically, we predicted that race category would bias sex categorizations due to common facial cues and overlapping stereotypes.

\section{Social Perception Biases From Intersecting Identities}

People fall into multiple social categories simultaneously, and this complexity affects several aspects of social perception. Motivations often dictate which social category (e.g., race or sex) captures attention and elicits stereotyped cognitions (Bodenhausen \& Macrae, 1998; Bodenhausen, Macrae, \& Sherman, 1999; Kurzban, Tooby, \& Cosmides, 2001; Pendry \& Macrae, 1996; Quinn \& Macrae, 2005). Additionally, some categories (e.g., male and White) are default social judgments (Merrit \& Harrison, 2006; Smith \& Zárate, 1992; Stroessner, 1996; Zárate \& Smith, 1990), making these categorizations more likely and more efficient, on average, than other categorizations. Consequently, individuals who have non-default identities for the intersection of sex and race 
suffer "intersectional invisibility," making Black women go largely unnoticed (Purdie-Vaughns \& Eibach, 2008; Sesko \& Biernat, 2010).

Moreover, the implications of intersecting identities also extend to other social perceptions. For instance, Goff, Thomas, and Jackson (2008) found that Black men and women were judged as more masculine and race stereotypical than same-sex White targets, leading Black women to be judged as physically unattractive. These authors also found that sex categorization errors, although rare, were more common for Black women than any other race/sex combination. Investigating the intersection of age and race on emotion perceptions, Kang and Chasteen (2009) found that the perceived onset and duration of happiness and anger depended on both race and age. Specifically, perceivers detected anger earlier and judged it to endure longer for younger, relative to older, Black men. Additionally, perceivers judged happiness to disappear earlier and to be shorter lived for younger Black men. The opposite occurred for perceptions of White men.

Collectively, these findings suggest that social perceptions are affected by intersecting identities. Yet, neither the scope of the effects nor the mechanisms that underlie such biases are clear. We propose that such effects may be widespread, impacting the earliest stages of social perception, categorizations. Specifically, we propose that race categories may bias sex categorization via two routes-one stemming from common facial cues, the other emerging through shared social stereotypes.

\section{A Bottom-Up Route to Biases in Sex Categorization}

A bottom-up route by which race may bias sex categorization centers on the possibility that the facial morphologies associated with different race and sex categories covary. If correct, race may bias sex categorization through common facial cues.

Importantly, race-cuing features have a pronounced effect on other aspects of social perception. For example, social categorization is swayed by visual cues such as hairstyle (Freeman, Ambady, Rule, \& Johnson, 2008; MacLin \& Malpass, 2001, 2003; Martin \& Macrae, 2007; Rule, Ambady, Adams, \& Macrae, 2008) or emotion expression (Hugenberg \& Bodenhausen, 2003, 2004; Hutchings \& Haddock, 2008). The prototypicality of Black faces determines the level of stereotypic attributions (Blair, Judd, Sadler, \& Jenkins, 2002), perceptions of skin tone (Levin \& Banaji, 2006), and even severity of criminal penalties (Blair, Judd, \& Chapleau, 2004; Eberhardt, Davies, Purdie-Vaughns, \& Johnson, 2006).

Race-cuing features also share overlaps with the features associated with other categories, specifically emotions. Zebrowitz, Kikuchi, and Fellous (2010) demonstrated that some emotion expressions shared certain features associated with Black, White, and Korean faces. These overlaps contribute to overgeneralization in social judgments (Zebrowitz, Fellous, Mignault, \& Andreoletti, 2003). Evaluative judgments that stem from stereotypes may be mitigated, for example, when Black men's faces exhibit disarming characteristics such as neotenous features (Livingston \& Pearce, 2009) or cues common to happy expressions (Zebrowitz et al., 2010).

These findings collectively highlight not only the importance of race-cuing features for an array of social perceptions but also how overlaps between race-cuing features and other categories moderate evaluative judgments. It may be that salient overlaps exist at the intersection of race and sex categories. Indeed, Black faces are perceived as more masculine than White faces (Goff et al., 2008). This suggests that the average Black face may be phenotypically similar to the average man's face. If correct, this would lead male categorizations to be more efficient for Black, relative to White or Asian, faces, but female categorizations to be less efficient for Black, relative to White or Asian, faces. Although it is possible that similar overlap exists between Asian faces and either male or female faces, less empirical evidence suggests this overlap.

\section{A Top-Down Route to Biases in Sex Categorization}

A top-down route by which the perception of race may bias sex categorization centers on the substantive overlap between some components of race and gender stereotypes. Race may therefore bias sex categorization through shared stereotypes.

Knowledge of social categories has a pronounced influence on the perception and interpretation of other social information. For instance, sex categorizations change the standards that are applied when observers make judgments of men versus women (Biernat, 2005; Biernat \& Manis, 1994; Johnson \& Tassinary, 2007a, 2007b). Activating one relevant stereotype constrains the impact of unrelated stereotypic or trait information during impression formation (Kunda \& Thagard, 1996). Thus, social categorization and the concomitant stereotypes that become activated constrain impression formation by changing the meaning of information or altering its impact. These findings provide a theoretical foundation for our prediction that race category may impact sex categorizations through shared stereotypes.

Importantly, some evidence suggests that overlaps between race and sex stereotypes exist. Many have argued, for example, that the stereotypes associated with various social categories-including race-reflect common underlying dimensions that are inherently gendered. Wiggins (1991) argued for the primacy of Agency and Communion as the building blocks of social perception and discussed the tight coupling between sex-roles and these constructs. This sentiment has been echoed by others who, although they adopt different labels, share the common belief that evaluative judgments fall along two primary dimensions (Abele, Uchronski, Suitner, \& Wojciszke, 2008; Fiske, Cuddy, \& Glick, 2007; Fiske, Cuddy, Glick, \& Xu, 2002; Park, Smith, \& Correll, 2008; Pinel Long, \& Crimin, 2008) that are sex-typed to some degree (Bosak, Sczensny, \& Eagly, 2008; Park et al., 2008; Wiggins, 1991).

Moreover, the dimensions of warmth and competence reveal some overlaps between race and sex categories, particularly for evaluative judgments (Cuddy, Fiske, \& Glick, 2008; Fiske et al., 2007). For instance, Asians and men tend to cluster, showing higher perceived competence than warmth; women and Whites tend to cluster, showing slightly less perceived competence but greater warmth than men and Asians; finally, Blacks tend to show the lowest levels of perceived competence but show perceived warmth that is equivalent to men and Asians (Fiske et al., 2002). Similar tendencies are evident cross-culturally (Cuddy et al., 2009). Evaluative rankings tend to shift, however, when more information is provided about each social target (e.g., "poor" Blacks or "sexy" women; Fiske et al., 2002). This model has undisputed implications for predicting valenced judgments (e.g., responses of admiration, envy, contempt, and prejudice; Fiske et 
al., 2002); yet, its utility for predicting the biasing impact of intersecting identities for social categorization is less clear.

More relevant to our hypotheses is the specific stereotype content that becomes active in working memory upon seeing a member of a specific group. The stereotypes of both Asians and women, for example, share the traits shy, family-oriented, and soft-spoken (Bem, 1974; Devine \& Elliot, 1995; Karlins, Coffman, \& Walters, 1969; Spence, Helmreich, \& Strapp, 1974). Similarly, the stereotypes of both Blacks and men share the traits aggressive, dominant, athletic, and competitive (Bem, 1974; Devine \& Elliot, 1995; Ho \& Jackson, 2001; Spence et al., 1974).

These overlaps may have implications for social categorization. Early in person construal, visual cues to each relevant social category are likely to elicit partial activation of associated stereotypes. This activation may facilitate or hinder a perceiver's ability to categorize a target's sex, depending on whether the content of the orthogonal stereotype is in accord or in conflict with the relevant judgment (see, e.g., Freeman \& Ambady, 2011). Therefore, relative to sex categorizations of White men, categorizations should be more efficient for Black men but less efficient for Asian men due to the relatively high level of overlap in race and sex stereotypes for Black men, but relatively low level of overlap in race and sex stereotypes for Asian men. Similarly, relative to sex categorizations of White women, categorizations should be more efficient for Asian women but less efficient for Black women, due to the relatively high and low overlaps, respectively, for race and sex stereotypes.

\section{Overview of Current Research}

We propose that race will bias sex categorization through common cues and/or overlapping stereotypes, both leading to similar predictions. Asian faces, for instance, may share phenotypes and/or activate stereotypes that are also common to women. Similarly, Black faces may share phenotypes and/or activate stereotypes that are also common to men. If correct, this should systematically bias the efficiency of sex categorization, over and above what is expected based on the existing and pronounced bias to perceive targets to be male (Merrit \& Harrison, 2006; Smith \& Zárate, 1992; Stroessner, 1996; Zárate \& Smith, 1990). A race category associated with phenotypes or stereotypes that are at odds with the target's sex category membership should impair sex categorization, and a race category associated with phenotypes or stereotypes that align with the target's sex category membership should facilitate sex categorization.

Consequently, we predicted that in addition to an overall tendency to more rapidly categorize men (Merrit \& Harrison, 2006; Smith \& Zárate, 1992; Stroessner, 1996; Zárate \& Smith, 1990), the race of targets would show a consistent and predictable bias on sex categorizations. We predicted that male categorizations would be more efficient for Black faces, but less efficiently for Asian faces, relative to White faces. We predicted that female categorizations would be less efficient for Black faces, but more efficiently for Asian faces, relative to White faces.

We used a multi-method approach to test these ideas. Our stimuli varied the race and sex of computer-generated faces and facial photographs. In Study 1, we examined how race systematically biased observers' sex categorizations of gender-ambiguous faces. In Study 2, we measured the degree race bias on sex categorizations by measuring the efficiency of judgments. In Studies 3 and 5, we tested the viability of a bottom-up route to biased categorization by measuring the degree of common facial cues for race and sex (Study 3) and examining their impact on categorizations (Study 5). In Studies 4 and 5, we tested the viability of a top-down route to biased categorization by measuring participants' strength of implicit associations between race and sex categories using a modified Implicit Associations Test (IAT; Greenwald, Nosek, \& Banaji, 2003) and relating it to biases in categorizations.

\section{Study 1}

\section{Method}

Participants. Seventy-seven undergraduate students (31 men, 46 women) participated in exchange for course credit.

Stimuli and procedure. Stimuli depicted gender-ambiguous faces that varied continuously in apparent race (Black, White, Asian). Faces were created using commercial software (FaceGen Modeler). ${ }^{1}$ Using the random generation feature of the software, we created 22 androgynous Caucasian faces at a level of gender in between the male and female means. Then, beginning with the Caucasian faces as a starting point, we used the Race Morphing Tool to vary the apparent race of each face. We included one intermediate level of Asian and Black and one more extreme level of Asian and Black to yield five levels of race from Black to Caucasian to Asian (see Figure 1a). Altogether, this provided a total of 110 stimuli that we cropped to reveal only the internal facial structure.

Our rationale for using a Caucasian face as the "base" for the race manipulation was based on prior theoretical and empirical work. Specifically, manipulating race category from a Caucasian starting point was warranted, in part, because "White" tends to serve as a default for social perception in White-majority environments (Merritt \& Harrison, 2006; Purdie-Vaughns \& Eibach, 2008; Stroessner, 1996; Zárate \& Smith, 1990). Additionally, the hypothesized directional relationship between the categories Asian/female and the categories Black/male suggest that this manipulation provided a continuum of race for which effects could be estimated relative to Caucasian faces.

\footnotetext{
${ }^{1}$ FaceGen Modeler makes use of a three-dimensional morphable statistical face model based on anthropometric parameters of the human population (Blanz \& Vetter, 1999). The program exploits the parameters that were observed in hundreds of three-dimensional face scans. Based on these observed multidimensional functions, we used FaceGen to create novel faces that are characteristic of the observed features for particular groups. Consequently, the random generate feature in FaceGen utilized a probability distribution to create a novel face that characterized, for example, a Caucasian face. Then, we used the Race Morphing Tools to alter the race phenotype in a manner that morphed faces to incorporate the characteristics that typify Asian and Black faces, again based on an observed probability distribution in multidimensional space. Thus, rather than changing an individual feature to modify the apparent race of each target, FaceGen altered each face in a multidimensional manner that represents observed variability among groups. Importantly, to the extent that the phenotypes for race and sex categories covary, this program should faithfully represent those common cues because it generates faces based on observed group differences, making this an ideal tool to examine not only top-down but also bottom-up mechanisms that contribute to our effects.
} 
a. Gender-Ambiguous Faces Varying in Race

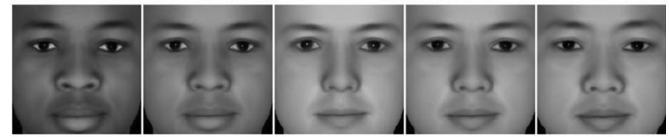

b. Male and Female Faces Varying in Race

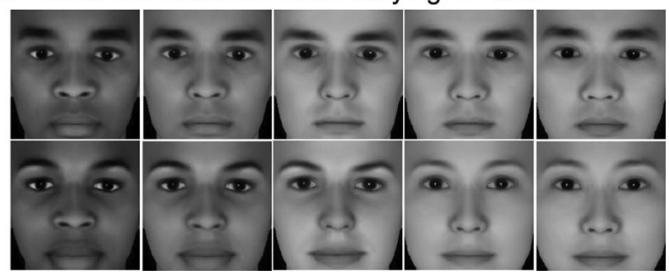

Figure 1. Sample face stimuli. (a) Gender ambiguous stimuli varying by race used in Study 1. (b) Stimuli varying by race and sex used in Studies $2-5$.

Participants arrived to the laboratory individually, were greeted by an experimenter, and were seated in front of a PC running customized stimulus presentation software. Participants were told that they would be making sex category judgments via buttons labeled "male" and "female" on the computer keyboard. For each trial, a fixation cross appeared on the computer screen for $500 \mathrm{~ms}$, followed by a face that appeared, centered on the computer monitor, until the participant rendered a judgment. Participants categorized each of the 110 faces, presented randomly, to be either male or female via button press. Both the judgment and response latency were recorded automatically.

\section{Results and Discussion}

Because the design was completely within subject, data were analyzed using generalized estimating equations (GEE) that controlled for intra-individual correlations in residuals and accurately estimated logistic effects (Fitzmaurice, Laird, \& Ware, 2004). We report unstandardized regression coefficients. We initially included participant sex as a factor in all analyses. No main effect or interaction involving participant sex reached significance (all $p \mathrm{~s}>$ $.19, n s)$; it was therefore dropped from analyses. We coded Race and Perceived Sex numerically, and we centered Race at the Caucasian level $(-2=$ Black, $0=$ Caucasian, Asian $=2)$ and Perceived Sex at 0 (Male $=-1$, Female $=1$ ). To minimize the effects of outliers, trials in which response times were more than $\pm 3 S D$ s away from the mean were excluded (for a similar technique, see Quinn \& Macrae, 2005). Inclusion of these trails in analyses did not change the overall pattern of results or their interpretation.

We predicted that Race would affect sex categorizations. To test this, we regressed sex category judgment onto Race using the binomial distribution option for our GEE analysis. We found that as race changed from Black to Caucasian to Asian, the probability of a "female" judgment increased significantly, $B=0.2196, S E=$ $0.0147, z=14.34, p<.0001$ (see Figure 2a). Each change in Race made "female" categorizations $24.55 \%$ more likely (odds ratio $=$ 1.24; Hosmer \& Lemeshow, 2000, p. 49). Consequently, the more extreme Asian faces were over twice as likely to be categorized as women, relative to the more extreme Black faces (odds ratio $=$ 2.40).

It is noteworthy that in spite of these patterns, perceivers exhibited a significant "male" categorization bias, intercept $B=-0.679$, $S E=0.0346, z=-19.65, p<.0001$. Indeed, the overall probability of a "female" categorization was only $33.65 \%$. Moreover, the level of manipulated race that would compel a sex-neutral judgment was highly Asian. To estimate this, we used the regression equation to solve for a predicted value of .5 (representing a hypothetically sex-neutral judgment). The race "threshold" at which categorizations would shift from being predominantly male to predominantly female was for an Asian face that was more extreme than our stimulus variation (Race value $=5.3912$ ). This is consistent with other work showing a male default in social judg-
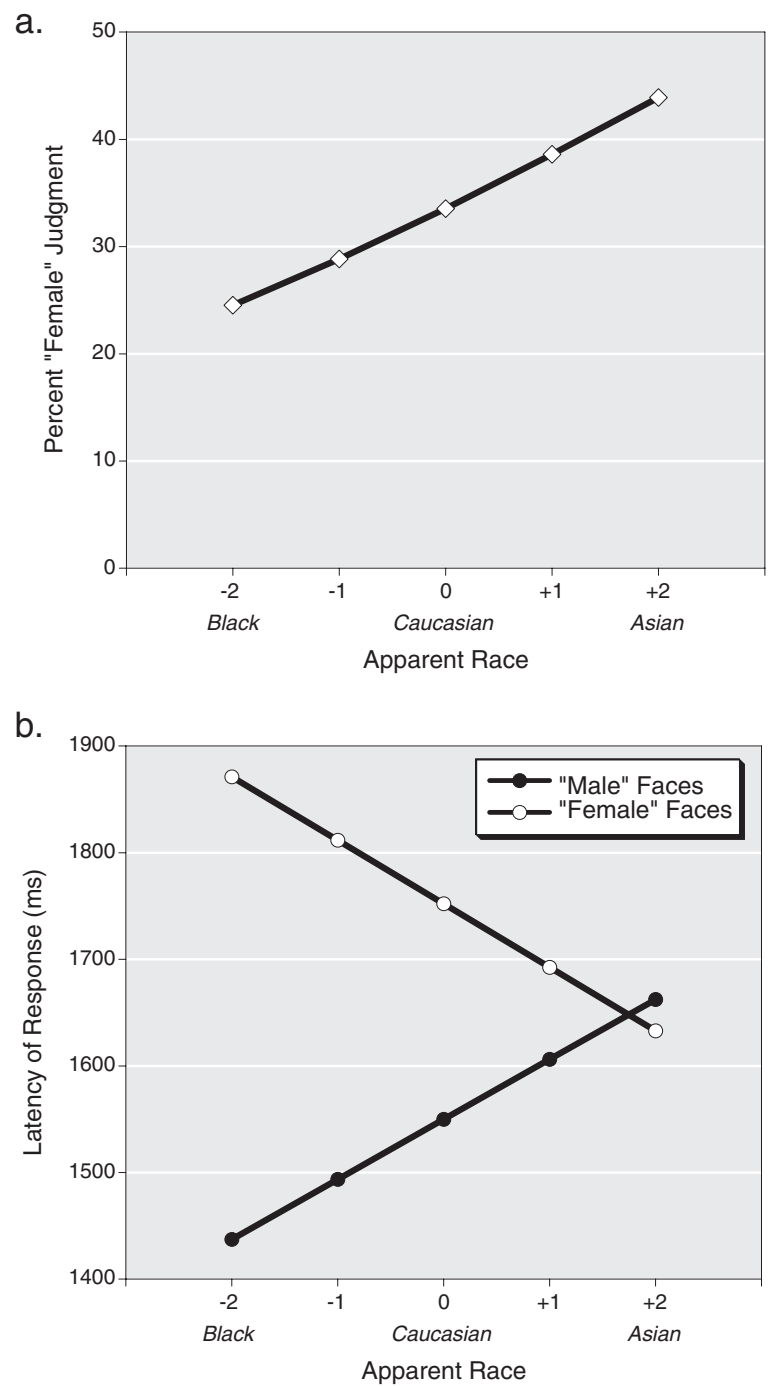

Figure 2. Predicted values for (a) the percentage of female judgments in sex categorization and of (b) latency of response as a function of race and sex categories in Study 1. Predicted values for the percentage of "female" categorizations were estimated by converting predicted logit values to percentages. Predicted values for latency of response were computed using the numeric coding values. 
ments (e.g., Purdie-Vaughns \& Eibach, 2008; Stroessner, 1996; Zárate \& Smith, 1990).

To determine whether the efficiency of judgments varied by Race and Sex, we regressed response latency onto Race, Perceived Sex (recoded and centered as male $=-.5$, female $=.5$ ), and their interaction. Overall, "male" categorizations were made more quickly than "female" categorizations, resulting in a significant effect for Perceived Sex, $B=114.6353, S E=16.2989, z=7.03$, $p<.0001$. The effect of Race was not significant, $B=-1.2003$, $S E=10.7478, z=-0.11, p=.91$. Most importantly, the interaction of Race and Sex was significant, $B=-57.9002, S E=$ 7.4362, $z=7.7863, p<.0001$ (see Figure 2b). As Race changed from Black to Asian, response latency decreased for female categorizations, simple $B=-59.5753, S E=13.0074, z=4.5801, p<$ .0001 , but increased for male categorizations, simple $B=56.2251$, $S E=7.0349, z=7.9923, p<.0001$.

Although sex and race vary orthogonally in reality, the two appeared to be confounded psychologically. Sex categorization as measured by actual judgments and response latencies was biased by a presumably task-irrelevant social category, race. The probability of and speed when making a female categorization increased significantly as race changed from Black to White to Asian.

\section{Study 2}

In Study 2, we sought convergent evidence for our proposal that the race would bias sex categorizations. Participants categorized the sex of faces that varied by Race and Sex. We predicted that although race was presumably irrelevant, Asian faces would facilitate "female" categorizations, and Black faces would facilitate "male" categorizations. If correct, race should bias sex categorization. Therefore, although observers are relatively unlikely to miscategorize sex, categorizations of Asian Men and Black Women should exhibit signs that both the actual and competing sex categories are compelling the earliest stages of the judgment task. We therefore recorded a behavioral index of the competition between the male and female response alternatives by recording the trajectory of computer mouse movements as participants made judgments.

Mouse tracking is a valid measure of the temporal dynamics of a competition between lexical, phonological, or semantic alternatives, including judgments of both self and social relevance (Dale, Kehoe, \& Spivey, 2007; Freeman \& Ambady, 2010; Freeman et al., 2008; McKinstry, Dale, \& Spivey, 2008; Spivey \& Dale, 2006; Wojnowicz, Ferguson, Dale, \& Spivey, 2009). Here, we use the technique to establish the simultaneous activation of multiple social category alternatives. When competition is low, mouse trajectories should be direct- exhibiting relatively straight movement toward the chosen category option, disregarding the competing category. Similarly, response latencies should be relatively short. We predicted that this pattern would characterize the sex categorizations of Black Men and Asian Women. When competition between category alternatives is high, in contrast, mouse trajectories should be more divergent-gravitating a bit toward the unselected (but partially activated) category alternative. Similarly, response latencies should be relatively long. We predicted that this pattern would characterize the sex categorizations of Asian Men and Black Women.

\section{Method}

Participants. Sixty-six undergraduate students (16 men, 50 women) participated in exchange for course credit.

Stimuli and procedure. Stimuli depicted computergenerated faces that varied in apparent Race and Sex. We used the same technique described in Study 1 to create our new stimulus set. We created 30 White faces (15 men, 15 women) using the Random Generation Tool of FaceGen Modeler. This provided 30 unique faces that characterize men's and women's faces, based on an observed probability distribution. Then, the apparent race of each face was manipulated to include five levels on a continuum from Black to Caucasian to Asian (see Figure 1b). Altogether, this yielded 150 distinct stimuli that we cropped to reveal only the internal facial structure.

Participants arrived to the laboratory individually, were greeted by an experimenter, and were seated in front of a PC running customized stimulus presentation software. Participants were told that they would be making sex category judgments via buttons labeled "male" and "female" using the computer mouse.

For each trial, a fixation cross appeared on the computer screen for $500 \mathrm{~ms}$, followed by a face that was presented in the bottomcenter of the computer screen. The mouse cursor was placed in the center of the face at the beginning of each trial. Boxes labeled "male" and "female" appeared in the upper corners of the screen (left/right position was counterbalanced across participants). Participants mouse-clicked the box that corresponded to their judgment for each of the 150 faces, presented in a randomized order. The judgment, response latency, and the $x$ and $y$ coordinates of the mouse trajectory were recorded automatically for each trial.

To record and analyze mouse trajectories, we used the MouseTracker software package (http://mousetracker.jbfreeman.net; Freeman \& Ambady, 2010). Trajectories were time-normalized by fitting them into 101 time steps using linear interpolation (to permit comparisons across trials with different trajectory lengths) and were converted to a coordinate space (left category alternative $[-1,1.5]$, right category alternative $[1,1.5]$, beginning mouse position $[0,0])$. We computed the point of maximum deviation from an ideal response trajectory (a straight line between a trajectory's start and end points) such that 0 represented a straight line; positive values represented movement in the direction of the competing, incorrect category (indexing simultaneous activation of that category); and negative values reflected departure away from the competing category.

\section{Results and Discussion}

We again analyzed data using GEE and report unstandardized regression coefficients. We initially included participant sex as a factor in all analyses. Some interactions involving participant sex did reach significance, ${ }^{2}$ but they did not change the interpretation

\footnotetext{
${ }^{2}$ Specifically, the three-way interaction between Participant Sex, Stimulus Sex, and Stimulus Race was significant for response latencies but not for mouse trajectories, $B \mathrm{~s}=-64.53$ and $0.003, S E \mathrm{~s}=26.18$ and 0.0097 , $z \mathrm{~s}=-2.46$ and $0.31, p \mathrm{~s}=.01$ and .7573 . In both cases, however, the interaction between Stimulus Sex and Stimulus Race remained strong and significant for both male and female participants, all zs $>2.43$, all $p \mathrm{~s} \leq$ .01 . Thus, although the magnitude of the effect was slightly larger among female perceivers, the pattern of data remained the same.
} 
of key variables of interest. Consequently, participant sex was dropped from these analyses. We coded target Race and Sex numerically, and we centered Race at the Caucasian level $(-2=$ Black, $0=$ Caucasian, Asian $=2$ ) and Sex at 0 (Male $=-1$, Female $=1$ ). To minimize the effects of outliers in this and all subsequent studies, trials in which response times were more than $\pm 3 S D$ s away from the mean were excluded as were trials in which sex was miscategorized (for a similar technique, see Quinn \& Macrae, 2005). Inclusion of these trails in analyses did not change the overall pattern of results or their interpretation.

Mouse trajectories. We predicted that participants' mouse trajectories would reveal biases in sex categorizations. To test this prediction, we regressed maximum deviation onto Race, Sex, and their interaction. As predicted, mouse trajectories, specifically their maximum deviation from an ideal straight line trajectory, varied as a function of Race and $\operatorname{Sex}, B=-0.0319, S E=0.0036$, $z=-8.8611, p<.0001$ (see Figure 3a). The change from Black to Asian minimized deviations for female categorizations, simple $B=-0.0242, S E=0.0029, z=-8.3448, p<.0001$, but increased deviations for male categorizations, simple $B=0.0076, S E=$ $0.0021, z=3.6190, p=.0002$. Thus, for male faces, mouse trajectories were most direct for Black, but least direct for Asian,

a.
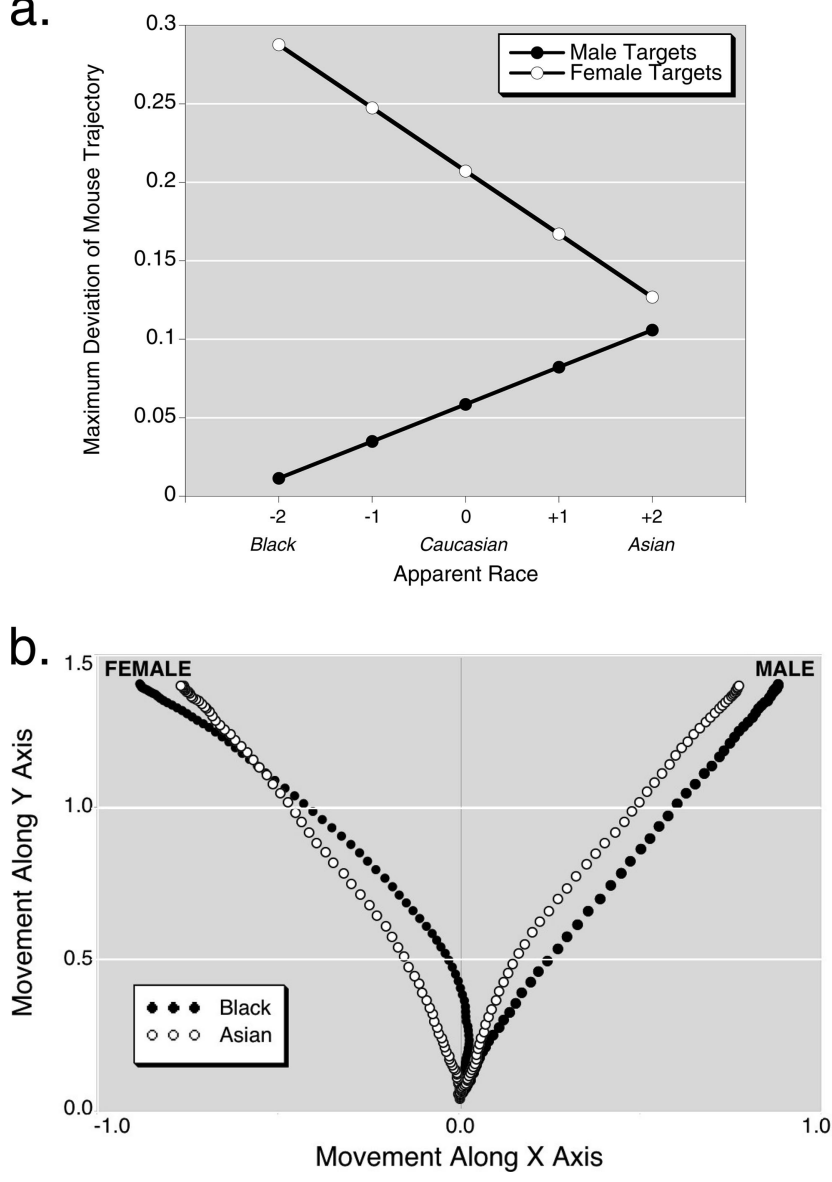

Figure 3. Predicted values for (a) maximum deviation as a function of race and sex categories and (b) time normalized mean mouse trajectories for the most and least divergent categories with in each sex in Study 2.

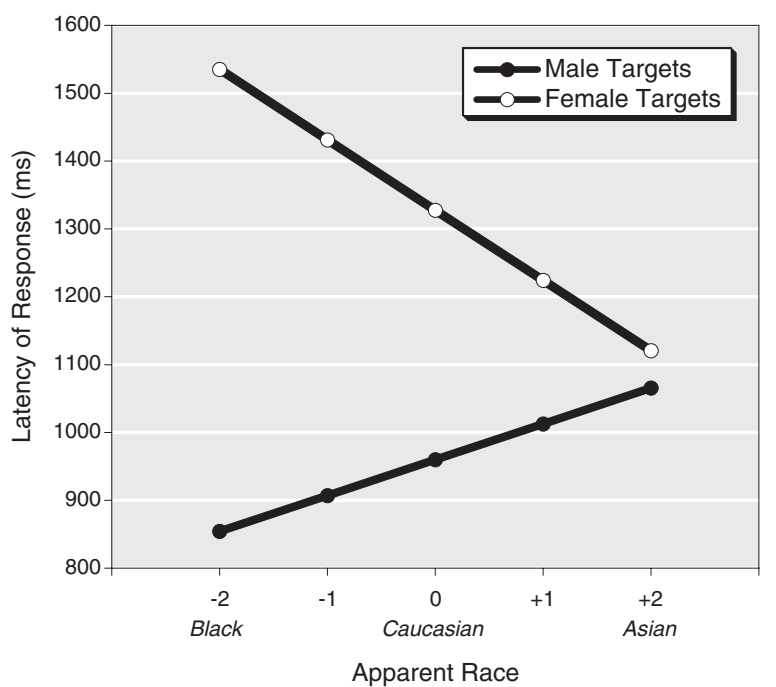

Figure 4. Predicted values for response latency as a function of race and sex categories in Study 2.

faces; for female faces, mouse trajectories were most direct for Asian, but least direct for Black, faces (see Figure $3 \mathrm{~b}$ for a plot of these trajectories)

Response latency. We also examined how response latency varied across the stimuli (see Figure 4). Replicating prior work, men were categorized more rapidly than women, $B=183.9145$, $S E=15.1385, z=12.1489, p<.0001$. Overall, response latency decreased as Race changed from Black to Asian, $B=-25.3824$, $S E=3.4954, z=-7.2617, p<.0001$. Most importantly, the predicted interaction between Race and Sex was significant, $B=$ $-78.2299, S E=6.9908, z=11.1904, p<.0001$. The change from Black to Asian corresponded to decreased response latency for female categorizations, simple $B=-64.4974, S E=5.7757, z=$ $11.1670, p<.0001$, but increased response latency for male categorizations, simple $B=13.7325, S E=3.9385, z=3.4867$, $p<.0001$.

Taken together, these findings demonstrate that race biases sex categorizations. For female targets, categorization of Asian faces was facilitated, and categorization of Black faces was impaired; the opposite was true for male targets.

\section{Interim Summary}

Studies 1 and 2 provide convergent evidence for the notion that race is gendered. Sex categorizations were biased by race category, even though the two varied orthogonally, affecting multiple dependent measures. Race affected the judgment made by participants as they disambiguated the sex category of androgynous faces (Study 1); it elicited behaviors that are consistent with the concurrent activation of competing category alternatives (Study 2 ), and it impacted the speed with which categorizations were made (Study 2).

The findings from these two studies demonstrate a robust pattern of bias in sex categorizations. They are mute, however, with respect to whether these effects were obtained through common facial cues or overlapping stereotypes. The remaining studies test these two possibilities. In Study 3, we assess the viability of a 
bottom-up route to bias by examining the degree to which sexually dimorphic facial features vary as a function of race and sex categories. In Study 4, we assess the viability of a top-down route to bias by examining the extent to which individual differences in perceivers' stereotype overlap (specifically for the categories Black and male and the categories Asian and female) moderate biases in sex categorization. In Study 5, we test the possibility that both routes operate in tandem to bias categorization, and we corroborate our effects by examining judgments of a new stimulus set.

\section{Study 3}

A bottom-up route to biases in sex categorization entails that facial phenotypes associated sex and race categories share common cues. In Study 3, we measured the degree of sex-typed facial morphology for faces that varied by Race and Sex. To the extent that sex-typed morphology varies as a function of Race category, it could bias sex categorization via a bottom-up route.

\section{Method}

Measurement of sex-typed morphology. We used FaceGen Modeler as a measurement tool, rather than for stimulus creation. Specifically, we quantified the degree sex-typed cues that covary with Race. Because FaceGen is based on a large database of three-dimensional face scans, it is ideally suited to provide such measurements. We included two sets of stimuli in our analysesphotographs and FaceGen images.

FaceGen provides a direct measure of the degree of sex-typing in its Gender Morph Scaling. Based on its population parameters, this tool reflects the linear probability that a particular phenotype belongs to a man or a woman. This is expressed in a scale, hereinafter called Phenotype, in which values range from -40 (highly male-typed) to +40 (highly female-typed). A value of 0 reflects an androgynous phenotype. For this study, we recorded the degree of sex-typed facial shape for each face using the Gender Morph Function.

Stimuli and procedure. First, we measured the extent of sex-typed facial morphology in facial photographs that varied in Race and Sex. We included 172 faces from widely used sources of facial stimuli (Chiao \& Ambady, 2001; Matsumoto \& Ekman, 1988; Minear \& Park, 2004; Tottenham et al., 2009). Faces were matched for age (approximately 18-29 years) and had neutral facial expressions, but they varied on the dimensions of interest: race and sex. These faces have been used extensively in prior research to examine facets of social perception including face processing, emotion recognition, person memory, and social categorization. We imported faces individually into the FaceGen Modeler using the PhotoFit Tool. Six faces failed to import because they were not fully frontal views, leaving 166 faces in the final set: Black (20 men, 19 women), White (38 men, 32 women), and Asian (34 men, 23 women).

Additionally, we measured the extent of sex-typed facial shape in a set of computer-generated faces. First, we created a new set of faces $(N=200)$ that varied in apparent Race and Sex using the techniques described in Studies 1 and 2. We created 40 Caucasian faces ( 20 men, 20 women) using the Random Generate Tool. Then, the apparent race of each face was manipulated to include five levels on a continuum from Black to Caucasian to Asian, as described in Study 1.

The faces generated using this technique are likely to reflect the proposed confounding between Race and Sex, to the extent that it exists in the human population. Importantly, the Random Generate function creates faces based on the known anthropometric variability that was estimated from hundreds of laser-scanned faces across the human population (Blanz \& Vetter, 1999). Thus, any phenotypic overlap between Race and Sex categories would also be inherent in newly created models. Therefore, this provides a measure of the degree of sex-typing for each category.

\section{Results and Discussion}

We analyzed the extent to which sex-typed facial appearance varied as a function of Race and Sex, separately for each stimulus set.

Real faces. We analyzed the degree of sex-typed facial shape for our photographs using a $2(\operatorname{Sex}) \times 3$ (Race) analysis of variance with Phenotype as the dependent variable (see the first panel of Table 1). As can be seen in the overall scores in Table 1, men exhibited more male-typed facial features, relative to women, $F(1,160)=126.605, p<.0001$. Importantly, sex-typed facial appearance also varied by Race, $F(2,160)=8.50, p<.0001$. Overall, Black faces were more male-typed than either White or Asian faces, $F \mathrm{~s}(1,160)=4.52$ and 2.59 , both $p s<.05$, and White

Table 1

Differences in Gender-Typed Facial Morphology as a Function of Race and Sex in Study 3

\begin{tabular}{|c|c|c|c|c|c|c|}
\hline \multirow[b]{2}{*}{ Photographs } & \multicolumn{5}{|c|}{ Target race } & \multirow[b]{2}{*}{ Overall } \\
\hline & Black & & White & & Asian & \\
\hline Men & $-8.95(1.23)$ & & $-1.11(0.89)$ & & $-2.12(0.92)$ & $-4.06(0.60)$ \\
\hline Women & $6.05(1.26)$ & & $7.25(0.97)$ & & $4.39(1.15)$ & $5.898(0.65)$ \\
\hline Overall & $-1.45(0.88)$ & & $3.07(0.66)$ & & $1.14(0.74)$ & $0.92(0.44)$ \\
\hline Computer-generated images & Black + & Black & White & Asian & Asian+ & Overall \\
\hline Men & $-27.70(0.57)$ & $-25.50(0.58)$ & $-23.20(0.56)$ & $-23.85(0.50)$ & $-24.40(0.51)$ & $-24.93(0.52)$ \\
\hline Women & $17.85(0.58)$ & $20.00(0.58)$ & $23.10(0.56)$ & $22.70(0.50)$ & $22.20(0.51)$ & $21.70(0.52)$ \\
\hline Overall & $-4.93(0.41)$ & $-2.75(0.41)$ & $-0.05(0.40)$ & $-0.58(0.35)$ & $-1.10(0.38)$ & $-1.88(0.36)$ \\
\hline
\end{tabular}

Note. Sex-typed facial morphology was determined using the Gender Morph Tool in FaceGen Modeler. Negative numbers are male-typed; positive numbers are female-typed; 0 is gender-neutral. Standard errors appear in parentheses. 
faces were more female-typed than Asian faces, $F(1,160)=1.94$, $p=.05$. Importantly, this pattern differed by target sex, $F(1$, $160)=7.265, p=.001$, resulting in a significant simple effect of Race for male, but not female, faces, $F_{\mathrm{S}}(2,160)=14.35$ and 1.81 , $p s<.0001$ and $n s$, respectively. These findings suggest that, on average, Black faces were the most male-typed, and that this pattern was more pronounced among men.

Computer-generated faces. Next, we analyzed sex-typed facial appearance of computer-generated faces using a $2(\operatorname{Sex}) \times$ 5 (Race) mixed-model analysis of variance with Race as a withintarget variable and Phenotype as the dependent variable (see the second panel of Table 1). We again found that men had more male-typed facial features, relative to women, $F(1,38)=$ $4,008.158, p<.0001$ (see overall differences). Once again, sextyped facial appearance varied by Race, $F(4,152)=198.598, p<$ .0001. Planned within-target contrasts that collapsed across the two levels of Black and the two levels of Asian faces were conducted. As seen in the overall differences, Black faces were more male-typed than either White or Asian faces, $F \mathrm{~s}(1,38)=$ $1,412.446$ and 152.8919 , both $p \mathrm{~s}<.001$, and White faces were more female-typed than Asian faces, $F(1,38)=11.2638, p=$ .001 . This pattern differed by target sex, $F(1,160)=7.265, p=$ .001 , but simple effects were significant for both male and female faces, $F \mathrm{~s}(1,38)=2,344.324$ and $1,690.498, p s<.001$, respectively. Thus, the sex-typing of computer-generated images largely mirrored what we observed among facial photographs.

We found that sex-typed cues varied as a function of race in both photographs and computer-generated stimuli. ${ }^{3}$ Across both stimulus sets, Black faces were, on average, more male-typed than either White or Asian faces. Thus, common facial cues may enable race biases in sex categorizations, especially for judgments of men. Specifically, Black faces may facilitate male categorizations because they exhibit more male-typed facial cues. Indeed, this is consistent with our findings in Studies 1 and 2.

These data provide little evidence, however, that Asian faces may facilitate female categorizations. Although Asian faces exhibited more female-typed appearance than Black faces on average, they were significantly less female-typed than White faces. This pattern is inconsistent with our findings in Studies 1 and 2, where we found that male categorizations were less efficient, but female categorizations were more efficient for Asian, relative to Black and White, faces. The results of Study 3 suggest that for Asian faces, biases in categorizations cannot be attributed to common facial cues. Instead, these biases may stem from overlapping stereotypes.

\section{Study 4}

A top-down route to biased social categorization entails that the stereotypes associated with race and sex categories share gendered content. We were concerned that explicit measures of such overlaps may create unwanted demand characteristics, so we elected to use a technique that would be less likely to be influenced by demand characteristics and that could tap associations of which participants themselves may be unaware. Thus, we measured implicit associations between race and gender using established techniques (Greenwald et al., 2003) and related these to the efficiency of sex categorizations. We predicted that participants who held relatively strong associations between the categories of Asian/female and the categories of Black/ male would exhibit stronger categorization biases. That is, we pre- dicted that implicit associations would moderate the strength of Race biases in sex categorization.

\section{Method}

Participants. Fifty undergraduate students (16 men, 34 women) participated in exchange for course credit.

Stimuli and procedure. Participants arrived to the laboratory individually, were greeted by an experimenter, and were seated in front of a PC running customized stimulus presentation software. Participants completed two tasks, in counterbalanced order.

In one task, we measured participants' implicit associations between the categories Asian and Female and the categories Black and Male using a modified IAT (Greenwald et al., 2003). Stimuli included 20 randomly generated faces (five each Asian/Black men and women) and 20 gendered adjectives (10 masculine, 10 feminine) selected from the masculine and feminine lists of the Adjective Check List (Heilbrun, 1976). ${ }^{4}$ The rationale to include only Black and Asian faces in this task was theoretically based. Specifically, these are the two race categories for which race stereotypes have shown overlap with sex stereotypes across the literature. Consequently, they comprised the most likely candidates for stereotype overlap. Additionally, the findings in Studies 1-3 bolster the notion that these race categories may be particularly likely to share stereotype content. Within the IAT, critical trials included congruent blocks (Black/male and Asian/female shared sides) and incongruent blocks (Asian/male and Black/female shared sides).

In another task, participants judged the sex category membership of 150 faces that varied by Race and Sex, using stimuli and procedures that were identical to Study 2. For each trial, a fixation cross appeared on the computer screen for $500 \mathrm{~ms}$, followed by a face, presented in the bottom-center of the computer screen. The mouse cursor was centered was placed at the center of the face at the beginning of each trial. Boxes labeled "male" and "female" appeared in the upper corners of the screen (left/right position was counterbalanced across participants). Participants mouse-clicked the box that corresponded to their judgment for each of 150 faces presented in a randomized order. Each face remained on the screen until the participant made a judgment. The judgment, response latency, and the $x$ and $y$ coordinates of the mouse trajectory were recorded automatically for each trial. Recoding and analysis of mouse trajectories used the same techniques described in Study 2.

\section{Results and Discussion}

Participants were categorized as having either high or low associations using a median split on their IAT score, $D$. Impor-

\footnotetext{
${ }^{3}$ It is important to note that our stimulus sets necessarily limit the generalizability of these findings. Because our images do not represent the global variation in facial phenotypes, it would be inappropriate to conclude that our findings generalize to that scale. That said, the fact that similar findings were obtained for both stimulus sets gives us confidence that the variations that we observed are reliable. Moreover, to the extent that the observed variability impacts perceivers' judgments, these images are an appropriate sample to test our propositions.

${ }^{4}$ Masculine items included the following: aggressive, arrogant, assertive, confident, dominant, forceful, hard-headed, outspoken, strong, and tough. Feminine items included the following: considerate, cooperative, dependent, forgiving, friendly, modest, sensitive, sincere, submissive, and timid.
} 
tantly, our methods and scoring followed the recommended format established in Greenwald et al. (2003). Thus, for our study, D reflected the relative ease for categorizing compatible trials (Black faces/masculine words and Asian faces/feminine words) over incompatible trials (Black faces/feminine words and Asian faces/ masculine words).

We again analyzed data using GEE, and we report unstandardized regression coefficients. We initially included participant sex as a factor in all analyses. No main effect or interaction involving participant sex reached significance (all $p s>.19, n s$ ); it was therefore dropped from these analyses. We coded Race and Perceived Sex numerically, and we centered Race at the Caucasian level $(-2=$ Black, $0=$ Caucasian, Asian $=2)$ and Perceived Sex at 0 (Male $=-1$, Female $=1$ ). As before, trials with extreme response latencies or errors were excluded from analyses. Inclusion of these trails in analyses did not change the overall pattern of results or their interpretation.

Mouse trajectories. We predicted that participants' degree of association between the categories of Asian/female and the categories Black/male would moderate the effect of Race and Sex on sex categorization. We regressed maximum deviation onto Sex, Race, IAT (high/low), and all interactions. We found that IAT scores moderated the interaction between Race and Sex for mouse trajectories' deviation at marginal significance, $B=-0.0108$, $S E=0.0058, z=-1.8621, p=.0622$ (see Figure 5). Among participants who held low implicit associations between the categories of Black/male and the categories of Asian/female, the interaction between Race and Sex did not predict mouse trajectories' deviation, simple interaction $B=-0.0168, S E=0.0103$, $n s$; among participants who held high implicit associations, in contrast, the interaction was strong, simple interaction $B=-0.0385$, $S E=0.0054, z=-7.1296, p<.0001$. For these participants, the change from Black to Asian elicited more direct mouse trajectories for female categorizations (i.e., less movement toward the competing male category alternative), simple $B=-0.0238, S E=$
0.0045, $z=-5.2889, p<.0001$, but elicited greater deviation in mouse trajectories for male categorizations (i.e., more movement toward the competing female category alternative), simple $B=$ 0.0147, $S E=0.0030, z=4.9000, p<.0001$.

Response latency. These effects replicated for response latency. Variation in implicit associations moderated the interaction between Race and Sex for response latency, $B=-13.1961, S E=$ $7.2274, z=-1.8258, p=.0679$ (see Figure 6). For participants who held low implicit associations, the interaction did not influence response latency, simple interaction $B=-19.9018, S E=$ $12.9335, n s$; for participants who held high implicit associations between race and sex, the interaction was strong, simple interaction $B=-46.2940, S E=6.4552, z=-7.1716, p<.0001$. For these participants, the change from Black to Asian corresponded to faster responses for female categorizations, simple $B=-26.5118$, $S E=5.5286, z=4.7954, p<.0001$, but slower responses for male categorizations, simple $B=19.7823, S E=3.3323, z=$ $5.9365, p<.0001$.

These findings provide converging evidence for our proposition that race is gendered, and they provide evidence for a top-down route by which race biases sex categorization. Here, we demonstrated that the degree of bias is predicted by an individual's level of implicit associations between the categories Black/male and the categories Asian/female. Importantly, strong implicit associations corresponded to biased categorizations for judgments of both men and women, albeit in opposite directions.

\section{Study 5}

Collectively, Studies 1-4 provide converging evidence for the notion that race biases sex categorization in a systematic manner. Additionally, Studies 3 and 4 demonstrated two routes by which such biases may occur-one the result of bottom-up influence from common cues associated with race and sex, the other the

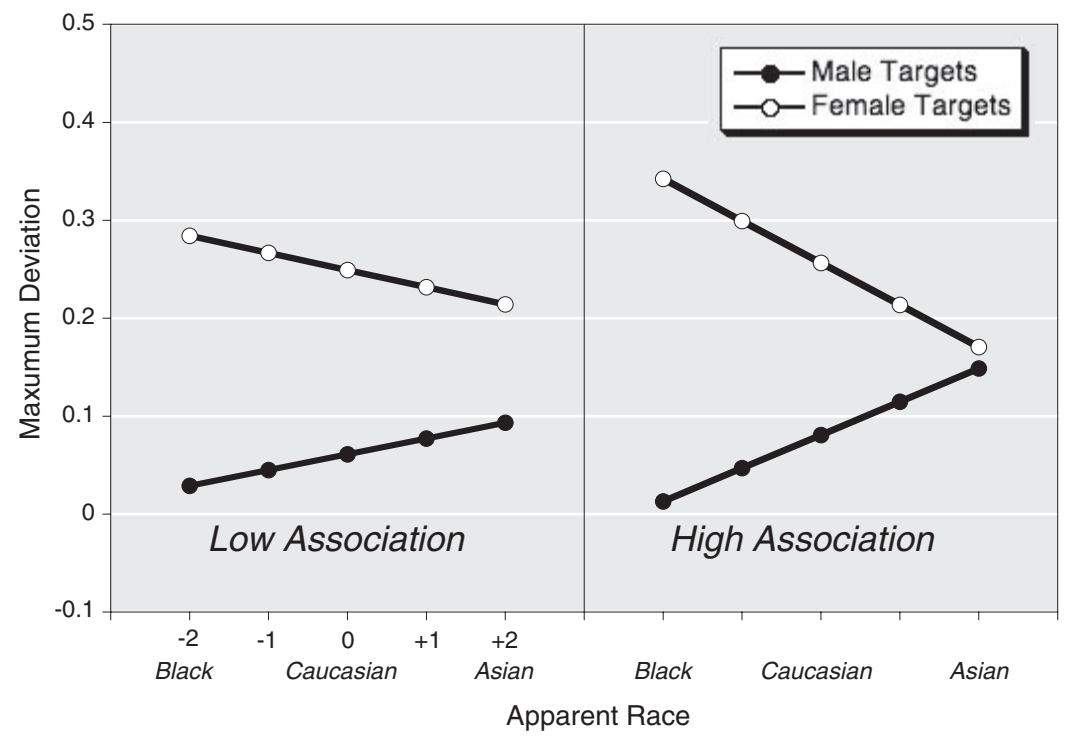

Figure 5. Predicted values for maximum deviation as a function of race and sex categories as a function of implicit associations, race, and sex in Study 4. 


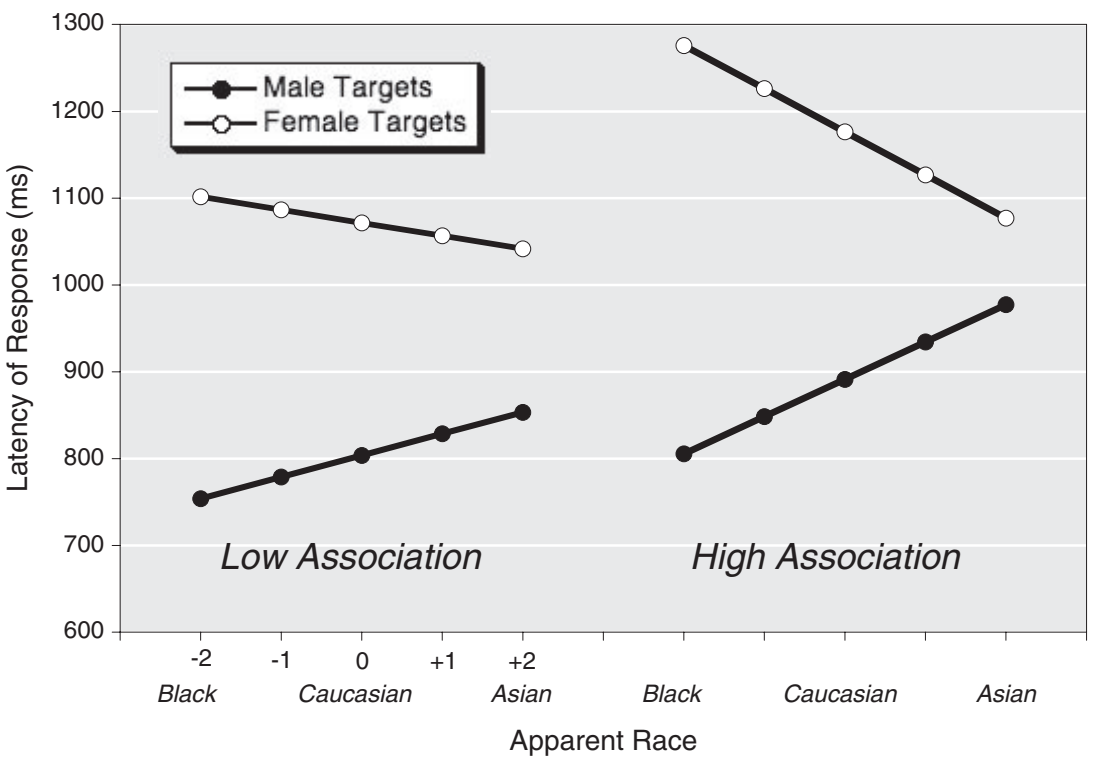

Figure 6. Predicted values for response latency as a function of race and sex categories as a function of implicit associations, race, and sex in Study 4.

result of top-down influence from a overlapping stereotypes associated with race and sex.

In Study 5, we sought corroborating evidence that race biases sex categorization via dual routes. First, we examined the generality of the top-down route to biases. We used different gendered adjectives, from more recent empirical work, for this IAT. Second, we used a stimulus set that permitted us to more critically evaluate the viability of the bottom-up route to biases. We tested the extent to which sex categorization biases were reduced after controlling for the degree of sex-typed facial cues.

\section{Method}

Participants. A total of 136 undergraduate students (32 male, 102 female, 2 unreported) participated in exchange for course credit.

Stimuli and procedure. Participants arrived to the laboratory individually, were greeted by an experimenter, and were seated in front of a Macintosh computer running customized stimulus presentation software. Participants then completed two tasks, which were run in counterbalanced order.

In one task, we measured participants' implicit associations between the categories Asian and Female and the categories Black and Male using a modified IAT (Greenwald et al., 2003). Stimuli included 24 randomly generated faces (six each Asian/Black men and women) and 24 gendered adjectives (12 masculine, 12 feminine) selected from work describing prescriptive gender stereotypes for men and women (Prentice \& Carranza, 2002). ${ }^{5}$ Critical trials included congruent blocks (Black/male and Asian/female shared sides) and incongruent blocks (Asian/male and Black/ female shared sides). Participants were categorized as having either high or low associations using a median split on their IAT score (i.e., D; Greenwald et al., 2003).

In another task, participants categorized the sex of 200 faces that varied by Race and Sex. Stimuli were identical to the computer- generated faces analyzed in Study 3. For each trial, a fixation cross appeared on the computer screen for $500 \mathrm{~ms}$, followed by a face that remained visible until the participant responded. Participants categorized each face to be either male or female via button press using keys labeled "male" and "female." Both the judgment and response latency were recorded automatically.

\section{Results and Discussion}

We again analyzed data using GEE, and we report unstandardized regression coefficients. We initially included participant sex as a factor in all analyses. One interaction involving participant sex did reach significance, ${ }^{6}$ but this effect did not change our interpretation of key variables of interest; thus, participant sex was dropped from these analyses. We coded Race and Target Sex numerically, and we centered Race at the Caucasian level $(-2=$ Black, $0=$ Caucasian, Asian $=2)$ and Target Sex at 0 (Male $=-1$, Female $=1)$. As before, trials with extreme response latencies or errors were excluded from analyses, but inclusion of these trails in analyses did not change the overall pattern of results or their interpretation. As before, participants were categorized as having

\footnotetext{
${ }^{5}$ Masculine items included the following: ambitious, athletic, assertive, business-sense, competitive, decisive, high-self esteem, leadership-ability, strong personality, and willing to take risks. Feminine items included the following: attention to appearances, cheerful, clean, cooperative, expresses emotion, friendly, patient, polite, sensitive, spiritual, warm, and wholesome.

${ }^{6}$ Specifically, the three-way interaction between Participant Sex, Stimulus Sex, and Stimulus Race was significant for response latencies, $B=$ 18.1684, $S E=6.7146, z=2.71, p=.0068$. Nevertheless, the interaction between Stimulus Sex and Stimulus Race remained strong and significant for both male and female participants, both $z \mathrm{~s}>6.0$, all $p \mathrm{~s} \leq .0001$. Thus, although the magnitude of the effect was slightly larger among male perceivers, the pattern of data remained the same.
} 
either high or low associations using a median split on their IAT score, $D$.

Replication analysis. First, we replicated the basic pattern of results. We regressed response latency onto stimulus Race, Sex, and their interaction. As can be seen in the first panel of Table 2, response latency decreased as Race changed from Black to Caucasian to Asian, $B=-6.6841, S E=1.3373, z=-5.00, p<.0001$. Male stimuli were categorized more quickly than female stimuli, $B=109.2474, S E=14.2078, z=7.69, p<.0001$. Again, the predicted interaction between Race and Sex was significant, $B=$ $-36.5331, S E=2.9342, z=-12.45, p<.0001$. The change from Black to Caucasian to Asian corresponded to decreased response latency for female faces, simple $B=-24.9507, S E=2.3395, z=$ $-10.67, p<.0001$, but increased response latency for male faces, simple $B=11.5824, S E=1.5518, z=7.46, p<.0001$. Thus, we replicated the pattern of responses in a new participant sample and using a different stimulus set.

Bottom-up influence. In Study 3, we found that Black faces were, on average, male sex-typed. This finding suggests that common cues are one route by which race may bias sex categorizations. If correct, the effect of race on sex categorizations should be significantly attenuated when common sex-typed cues are taken into account. We tested this possibility by testing whether the effect of race on sex categorization biases was eliminated after controlling for the sex-typed face shape (as measured by the degree of sex-typed face shape in Study 3; herein after called Phenotype).

We reasoned that to the extent that the categorization bias exists because of overlapping phenotypes, the effect of race on sex categorization should be substantially attenuated. We regressed latency of response onto Race, Sex, Phenotype (treated as a covariate), and all interactions (see Table 2). Phenotype as a covariate did not relate to response latency directly (controlling for other factors), $B=-0.6914, S E=0.767, z=-0.90, p=.37$. Yet, it did interact with both Race and Sex, $B \mathrm{~s}=0.8404$ and $-4.2334, S E \mathrm{~s}=$ 0.4416 and 1.6297, $z \mathrm{~s}=1.9$ and $-2.6, p \mathrm{~s}=.057$ and $<.01$, respectively. Most importantly, we found a significant three-way interaction, $B=3.3195, S E=1.0067, z=3.30, p=.001$. This interaction established that controlling for Phenotype had different implications for race to bias categorizations of men versus women.

With Phenotype's importance as a covariate established, we examined the simple main effect of race controlling for Phenotype, separately for male and female categorizations. As seen in the second panel of Table 2, controlling for Phenotype eliminated the effect of race on sex categorizations of men, simple $B=-8.4875$, $S E=11.6525, z=-0.73, p=.4466$. In contrast, controlling for Phenotype did not eliminate the effect of race on sex categorizations of women, simple $B=-82.1991, S E=19.032, z=-4.32$, $p<.0001$. These findings suggest that common facial cues are sufficiently strong to bias sex categorizations of men but not of women.

These findings demonstrate the role of common cues for race biases in sex categorizations. Specifically, sex-typed facial cues are common to the categories Black and male. Consequently, sex categorizations of men are swayed by race categories in a bottom-up fashion, as evidenced by the elimination of a race effect for categorizations of men when Phenotype had been statistically controlled. An analogous effect was not observed, however, for categorizations of women. Instead, the effect of race remained strong and significant for categorizations of women. This pattern suggests that although common cues may bias male categorizations, other factors bias female categorizations.

Top-down influence. In Study 4, we found that race biased sex categorizations through shared stereotype associations between the categories Asian/female and the categories Black/male Here, we tested both the generality and specificity of this effect.

Table 2

Response Latencies as a Function of Race and Sex in Study 5

\begin{tabular}{|c|c|c|c|c|c|c|}
\hline \multirow[b]{2}{*}{ Replication analyses } & \multicolumn{5}{|c|}{ Target race } & \multirow[b]{2}{*}{ Overall } \\
\hline & Black + & Black & White & Asian & Asian+ & \\
\hline Men & $1,225.56$ & $1,237.14$ & $1,248.72$ & $1,260.31$ & $1,271.89$ & $1,248.72$ \\
\hline Women & $1,407.87$ & $1,382.92$ & $1,357.97$ & $1,333.02$ & $1,308.07$ & $1,357.97$ \\
\hline Overall & $1,316.72$ & $1,310.03$ & $1,303.48$ & $1,296.66$ & $1,289.98$ & $1,303.48$ \\
\hline Bottom-up influence of common cues & Black + & Black & White & Asian & Asian+ & Overall \\
\hline Men & $1,298.99$ & $1,290.51$ & $1,282.02$ & $1,273.53$ & $1,265.05$ & $1,282.02$ \\
\hline Women & $1,585.36$ & $1,503.16$ & $1,420.96$ & $1,338.76$ & $1,256.56$ & $1,420.96$ \\
\hline Overall & $1,442.18$ & $1,396.84$ & $1,351.49$ & $1,306.15$ & $1,260.81$ & $1,351.49$ \\
\hline Top-down influence of overlapping stereotypes & Black + & Black & White & Asian & Asian+ & Overall \\
\hline \multicolumn{7}{|l|}{ High-association participants } \\
\hline Men & $1,209.54$ & $1,222.95$ & $1,236.37$ & $1,249.79$ & $1,263.21$ & $1,236.37$ \\
\hline Women & $1,412.65$ & $1,380.01$ & $1,347.37$ & $1,314.73$ & $1,282.09$ & $1,348.96$ \\
\hline \multicolumn{7}{|l|}{ Low-association participants } \\
\hline Men & $1,237.78$ & $1,247.77$ & $1,257.77$ & $1,267.76$ & $1,277.75$ & $1,257.77$ \\
\hline Women & $1,425.93$ & $1,401.79$ & $1,377.65$ & $1,353.51$ & $1,329.37$ & $1,376.06$ \\
\hline Overall & $1,321.47$ & $1,313.13$ & $1,304.79$ & $1,296.45$ & $1,288.11$ & $1,304.79$ \\
\hline
\end{tabular}

Note. Predicted values for response latencies in Study 3, separately for (a) replication analyses, (b) controlling for sex-typed facial morphology, and (c) moderated by Implicit Associations Test level. 
We regressed response latency onto Race, Sex, IAT (high vs. low), and all interactions (see Table 2). Once again, response latency decreased as Race changed from Black to Caucasian to Asian, $B=-8.3422$, $S E=1.4743, z=-5.66, p<.0001$; male faces were categorized more rapidly than female faces, $B=$ 115.4399, $S E=15.1267, z=7.63, p<.0001$ (predicted $M \mathrm{~s}=$ $1,247.07$ and 1,362.51, respectively); and the interaction between Race and Sex was significant, $B=-40.0959, S E=3.0606, z=$ $-13.10, p<.0001$

As can be seen in the third panel of Table 2, the interaction between Race and Sex again varied with participants' level of implicit associations, resulting in a significant three-way interaction, $B=-5.9633, S E=3.0606, z=-1.95, p=.05$. The interaction between Race and Sex was stronger among participants who held strong implicit associations, relative to those who held weak associations, simple $B \mathrm{~s}=-46.0592$ and $-34.1326, S E \mathrm{~s}=$ 5.1467 and $3.3136, z \mathrm{~s}=-8.95$ and -10.3 , respectively, both $p \mathrm{~s}<$ .0001. Indeed, the effect of race impacted sex categorization for participants who held both high and low levels of association, albeit to different degrees, $B$ s for low-association participants = 9.99 and $-24.14, S E \mathrm{~s}=2.22$ and 3.03, $z \mathrm{~s}=4.51$ and -7.79 , for male and female targets, respectively, both $p \mathrm{~s}<.0001$, and $B$ s for high-association participants $=13.4187$ and -32.6403, SEs $=$ 2.0945 and $4.201, z \mathrm{~s}=6.41$ and -7.77 , for male and female targets, respectively, both $p \mathrm{~s}<.0001$.

To more fully understand the nature of these effects, we conducted internal analyses to determine whether the associations between Asian/female and Black/male differed in their strength. These analyses suggested that the $D$ measure was driven more strongly by associations between Asian and feminine than between Black and masculine. $^{7}$

Taken together, these findings corroborate the role of overlaps in stereotypes for biasing sex categorization-leading race to have a significantly stronger bias on sex categorization among participants for whom stereotypes for race and sex covary to a greater degree, perhaps driven largely by overlaps in the overlaps in stereotypes for Asians and women.

Combined influence. Thus far, our analyses have corroborated and extended our prior findings, suggesting that race biases sex categorizations due to common cues in Black and male faces and due to overlapping gendered stereotypes between the categories Asian and female. Next, we examined whether, taken together, common cues and overlapping stereotypes could account for the majority of the bias in sex categorizations.

In our analyses testing the role of overlapping stereotypes, the interaction between Race and Sex remained significant in both high- and low-association groups even though it varied in magnitude. Given our findings that Phenotype biased sex categorizations of men in a bottom-up fashion, we predicted that we could more fully account for sex categorization biases if we also controlled for common sex-typed cues. We therefore included Phenotype as a covariate in a hierarchical model.

Among participants who held low associations, controlling for common facial cues largely eliminated the interaction between race and sex, $B=-60.9955, S E=31.9040, z=-1.91, p=.06$. Among participants who held high associations, however, the interaction between race and sex remained significant, $B=$ $-87.4358, S E=25.2176, z=-3.47, p=.0005$.
To further probe this remaining race bias on sex categorizations, we tested the simple slopes of race for men and women within the high-association groups in this model. Among those participants holding high associations, controlling for Phenotype eliminated the effect of race for male categorizations, $B=-15.5333, S E=$ $14.6258, z=-1.06, p=.2882$, but not for female categorizations, $B=-102.969, S E=25.2696, z=-4.07, p<.0001$.

These findings clarify the role of both overlapping race and sex phenotypes and stereotypes in biasing sex category judgments. They imply that for most perceivers, race biases in sex categorization can be attributed largely to common cues and overlaps in stereotypes. Overlapping stereotype associations were implicated in the effect of race on sex categorization for both men and women. Indeed, we replicated the effect in which the impact of race category on sex category judgments is moderated by participants' level of associations between the categories Black and Male and the categories Asian and Female. The impact of race on sex categorizations was significantly lower for judgments made by participants who held weak associations, relative to those who held strong associations.

In spite of this moderation, common stereotypes appeared not to be the sole factor operating. We found that overlapping facial cues were sufficient to eliminate the effect of race for male, but not female, categorizations. Moreover, doing so eliminated the Sex $\times$ Race interaction entirely for participants who held weak stereotype associations.

These findings suggest that whereas stereotypes are implicated for biases in judgments of both men and women, phenotypes are implicated for biases only in judgments of men. These findings highlight dual routes by which race biases sex categorizations.

\section{General Discussion}

Across five studies, we documented that a target's race biased sex categorizations. Race influenced judgments as perceivers disambiguated the sex category of androgynous faces (Study 1). Female categorizations were facilitated, and male categorizations were impaired, as stimuli changed from Black to Caucasian to Asian (Studies 1, 3-5). Importantly, we identified two routes by which such effects occur. First, the overlaps in race and sex stereotypes impacted the efficiency of judgments via a top-down route. The race bias for sex categorizations was more pronounced among participants who held stronger associations for Asian/

\footnotetext{
${ }^{7}$ We compared reaction times for participants' race categorizations of faces as a function of trial type (compatible or incompatible) and face race. Not surprisingly, these analyses revealed that responses were marginally faster for compatible trials than incompatible trials overall, $B=-33.4782$, $S E=18.7372, z=-1.79, p=.07$, and for Black, relative to Asian, faces, $B=62.8829, S E=11.5201, z=5.46, p<.0001$. Importantly, however, the interaction was also significant, $B=-119.300, S E=26.9893, z=$ $-4.42, p<.0001$. Simple effects analyses suggested that participantgendered associations were driven more by the associations between Asians and feminine words than by the associations between Black and masculine words. Response latencies did not differ between Black or Asian faces when they were paired with stereotype-consistent gendered words, $B=3.2329, S E=13.6498, z=0.24, p=.8182$. Response latencies were significantly longer for Asian, relative to Black, faces when they were paired with stereotype-inconsistent gendered words, $B=112.5330, S E=$ $21.0551, z=5.82, p<.0001$.
} 
female and Black/male (Studies 4 and 5). Second, common cues in the facial phenotypes of Black and male faces impacted the efficiency of sex categorizations in a bottom-up fashion. Black faces were, on average, more male-typed than either White or Asian faces (Study 3), thus facilitating male categorizations. Thus, whereas stereotype overlap affected categorizations of both men and women, common cues affected categorizations of men.

\section{Implications for Other Aspects of Social Categorization}

Although our focus has been exclusively on how race affects sex categorizations, we suspect that similar biases will operate for other social categorizations and at other identity intersections. Indeed, the two routes to bias that we have described suggest the circumstances in which we would expect other forms of biased perceptions.

The stereotype overlaps for Black/male and Asian/female may extend beyond the social categories that we have examined here. Indeed, stereotypes associated with many social categories reveal the common underlying dimensions of warmth/competence (Fiske et al., 2007, 2002) or agency/communion (Abele et al., 2008; Wiggins, 1991). One might expect, therefore, that many social categorizations that are tethered to these fundamental dimensions would also exhibit biases via the top-down route that we have described. This opens the possibility that similar biases may exist for the judgment of men and women from other race categories or for other social category dimensions (e.g., sexual orientation; see Johnson \& Ghavami, 2011). That said, given the strongly gendered nature of the dominance/affiliation, warmth/competence, and agency/communion dimensions (Wiggins, 1991), sex categorizations may be more heavily impacted by orthogonal social categories, relative to other social categorizations.

Additionally, the common cues that we observed for Black/male suggests that the bottom-up impact of phenotype may operate bidirectionally. At least for judgments of men, perceiving sex category may alter the processing required for making a Black categorization, based solely on phenotypic overlap. Moreover, all of these processes are likely to be heavily affected by perceivers' motivations. In recent work, for example, perceivers who were motivated in a manner that pertained to personal safety were more likely to perceive men to be approaching them (rather than retreating) and to disambiguate biracial images to be Black (Miller, Maner, \& Becker, 2010).

Thus, the dual pathways leading to intersectional biases in social categorization provide an important foundation for understanding the other biases that are likely to occur in social perception. Although beyond the scope of the current article, the degree and range of these biases for other aspects of social categorization remain an interesting avenue for future research.

\section{Implications for Models of Social Perception}

These findings also have broad implications for models of social perception, especially when identities intersect. Specifically, our technique of varying apparent race on a continuum from Black to Caucasian to Asian, as opposed to the use of distinct Black/White categories in isolation, permitted a more comprehensive examination of the combinatorial nature of social categorization. We found that the race category of non-White targets did indeed impact sex categorization, but not by uniformly impairing judgments. Instead, we found systematic impairment of sex category judgments when stereotypes and phenotypes for race and sex categories were in conflict (e.g., Asian men and Black women) but systematic facilitation of judgments when stereotypes and phenotypes were in accord (Black men and Asian women).

Moreover, our finding that race heavily and systematically impacts sex categorization points to particular groups that are likely to be difficult to integrate in core race and sex categories. Indeed, based on both phenotype and stereotype overlaps, Black women and Asian men appear to pose greater processing challenge, relative to other race members of their same sex. Put simply, they are atypical. This might lead these particular categories to be represented as intersectional units and form the basis for subtyping (Hewstone, 1994; Hewstone \& Hamberger, 2000; Yzerbyt, Coull, \& Rocher, 1999). Although the vast majority of subtyping literature has examined how perceivers form impressions when traits or behaviors are at odds with group-based stereotypes (for a review, see Richards \& Hewstone, 2001), the mechanisms that lead perceivers to subtype in those circumstances may be relevant here as well. For instance, when bits of information about a social target are at odds (e.g., as in the classic example of the Harvard-educated carpenter), perceivers are prone to engage in causal reasoning to remedy the apparent conflict (see, e.g., Kunda, Miller, \& Claire, 1990; Kunda \& Thagard, 1996). This process leads perceivers to subtype individuals who violate expectations. Our findings suggest that this process might even operate at the level of basic categories as well. The covariance of race and sex categories-stereotypically and phenotypically_leads some specific combinations of race and sex to be experienced as atypical, therefore increasing the likelihood that individuals within these categories will be subtyped. Our data suggest that this is particularly likely to occur for Black women and Asian men, relative to other combined categories of race and sex. Thus, these findings provide an empirical foundation for those who have proposed that, under some circumstances, the unit of person representation may be combinatorial in nature (see, e.g., Shields, 2008).

This research also lends empirical support to the theoretical work describing intersectional invisibility (Purdie-Vaughns \& Eibach, 2008). We have shown that certain combinations of race and sex are atypical and that they require more extensive and effortful processing, relative to other combinations. This increased effort also raises the likelihood that perceivers will opt to forego more extensive processing of the individual, rendering Black women and Asian men intersectionally invisible.

Our findings also contribute to important research that has established stable judgment tendencies in social categorizations. Although we replicated the pronounced tendency for men to be categorized more rapidly than women (see Merrit \& Harrison, 2006; Smith \& Zárate, 1992; Stroessner, 1996; Zárate \& Smith, 1990), we also found variation around this tendency. Specifically, our findings suggest that within this well-documented social judgment bias, race categories impact sex categorization efficiency in opposite directions for men and women. Thus, our findings provide additional specificity to existing theoretical models of social perception.

Equally importantly, these findings dovetail nicely with current theoretical accounts and neural network models of person con- 
strual that emphasize the dynamic and interactive nature of social perception and cognition (Freeman \& Ambady, 2011). For instance, sensory cues have been argued to trigger a probabilistic mixture of partially active social categories, which reveal the dynamic nature of race attitudes (Wojnowicz et al., 2009) and social categorizations (Freeman \& Ambady, 2009; Freeman, Pauker, Apfelbaum, \& Ambady, 2010; Freeman et al., 2008; Johnson \& Freeman, 2010). One important tenet of this account is that person construals are the end-result of an ongoing, mutually constraining interaction between multiple information sources (e.g., lower-level sensory cues; higher-order cognitive states) that stabilize over time (Freeman \& Ambady, 2011). As such, higherorder processing (e.g., stereotype activation) may readily exert influences on lower-level processing (e.g., category activation). The implication is that the dynamic activation of stereotypes can actually constrain lower-level processing, such as categorization. Thus, partially activated race stereotypes, this dynamic interactive model of person construal, can seamlessly alter the sex categorization process. Here, we provided evidence for this exact kind of top-down "feedback" in person construal by showing that race stereotypes shape sex categorization.

\section{Conclusion}

Ultimately, this research should be viewed as a complement to studies that have focused primarily on the culmination of social categorization processes. Our work provides insights into the early processing governing social categorization, which sets the stage for cognitive representations of individuals. Indeed, the social categorization process may be less straightforward than merely extracting perceptual cues that belong to a particular category. As cues to social categories become more ambiguous and complex, which is often the case in situations outside the laboratory, social contexts, cultural associations, and motivation may increasingly influence perceivers (Pauker \& Ambady, 2009; Pauker, Rule, \& Ambady, 2010; Pauker et al., 2009). Our work highlights how person construal may be more malleable and dynamic than often assumed, describing how common facial cues and overlapping stereotypes may collaboratively work together to produce our ultimate social categorizations. Moreover, it helps account for how top-down information can influence social categorizations in systematically biased, sometimes self-serving ways (e.g., Hugenberg \& Bodenhausen, 2003, 2004). Additionally, these findings afford a foundation to better understand how intersectionality among social categories may contribute to negative social evaluation and groupbased discrimination.

\section{References}

Abele, A. E., Uchronski, M., Suitner, C., \& Wojciszke, B. (2008). Towards an operationalization of the fundamental dimensions of agency and communion: Trait content ratings in five countries considering valence and frequency of word occurrences. European Journal of Social Psychology, 38, 1202-1217. doi:10.1002/ejsp.575

Allport, G. W. (1954). The nature of prejudice. Reading, MA: AddisonWesley.

Bargh, J. A. (1999). The cognitive monster: The case against controllability of automatic stereotype effects. In S. Chaiken \& Y. Trope (Eds.), Dual process theories in social psychology (pp. 361-382). New York, NY: Guilford Press.
Bem, S. (1974). The measurement of psychological androgyny. Journal of Consulting and Clinical Psychology, 42, 155-162. doi:10.1037/ h0036215

Biernat, M. (2005). Standards and expectancies: Contrast and assimilation in judgments. New York, NY: Psychology Press/Taylor \& Francis. doi:10.4324/9780203338933

Biernat, M., \& Manis, M. (1994). Shifting standards and stereotype-based judgments. Journal of Personality and Social Psychology, 66, 5-20. doi:10.1037/0022-3514.66.1.5

Blair, I. V., Judd, C. M., \& Chapleau, K. M. (2004). The influence of Afrocentric facial features in criminal sentencing. Psychological Science, 15, 674-679. doi:10.1111/j.0956-7976.2004.00739.x

Blair, I. V., Judd, C. M., Sadler, M. S., \& Jenkins, C. (2002). The role of Afrocentric features in person perception: Judging by features and categories. Journal of Personality and Social Psychology, 83, 5-25. doi:10.1037/0022-3514.83.1.5

Blanz, V., \& Vetter, T. (1999). A morphable model for the synthesis of 3D faces. In Proceedings of the 26th Annual SIGGRAPH Meeting (pp. 187-194). Los Angeles, CA: Addison Wesley Longman.

Bodenhausen, G. V., \& Macrae, C. N. (1998). Stereotype activation and inhibition. In R. S. Wyer Jr. (Ed.), Stereotype activation and inhibition: Advances in social cognition (Vol. 11, pp. 1-52). Mahwah, NJ: Erlbaum.

Bodenhausen, G. V., Macrae, C. N., \& Sherman, J. W. (1999). On the dialectics of discrimination: Dual processes in social perception. In S. Chaiken \& Y. Trope (Eds.), Dual process theories in social psychology (pp. 271-290). New York, NY: Guilford Press.

Bosak, J., Sczesny, S., \& Eagly, A. H. (2008). Communion and agency judgments of women and men as a function of role information and response format. European Journal of Social Psychology, 38, 11481155. doi:10.1002/ejsp.538

Chiao, J., \& Ambady, N. (2001). Emotional expressions in White, Black, and Asian faces. Unpublished set of photographs.

Cloutier, J., Mason, M. F., \& Macrae, C. N. (2005). The perceptual determinants of person construal: Reopening the social-cognitive toolbox. Journal of Personality and Social Psychology, 6, 885-894. doi: 10.1037/0022-3514.88.6.885

Cuddy, A. J. C., Fiske, S. T., \& Glick, P. (2008). Warmth and competence as universal dimensions of social perception: The stereotype content model and the BIAS map. Advances in Experimental Social Psychology, 40, 61-149. doi:10.1016/S0065-2601(07)00002-0

Cuddy, A. J. C., Fiske, S. T., Kwan, V. S. Y., Glick, P., Demoulin, S., Leyens, J. P., ... Ziegler, R. (2009). Stereotype content model across cultures: Towards universal similarities and some differences. British Journal of Social Psychology, 48, 1-33. doi:10.1348/014466608X314935

Dale, R., Kehoe, C. E., \& Spivey, M. J. (2007). Graded motor responses in the time course of categorizing atypical exemplars. Memory \& Cognition, 35, 15-28. doi:10.3758/BF03195938

Devine, P. G. (1989). Stereotypes and prejudice: Their automatic and controlled components. Journal of Personality and Social Psychology, 56, 5-18. doi:10.1037/0022-3514.56.1.5

Devine, P. G., \& Elliot, A. J. (1995). Are racial stereotypes really fading? The Princeton trilogy revisited. Personality and Social Psychology Bulletin, 11, 1139-1150. doi:10.1177/01461672952111002

Dovidio, P. G., Evans, N., \& Tyler, R. P. (1986). Racial stereotypes: The content of their cognitive representations. Journal of Experimental Social Psychology, 22, 22-37. doi:10.1016/0022-1031(86)90039-9

Eberhardt, J. L., Davies, P. G., Purdie-Vaughns, V. J., \& Johnson, S. L. (2006). Looking deathworthy: Perceived stereotypicality of Black defendants predicts capital-sentencing outcomes. Psychological Science, 17, 383-386. doi:10.1111/j.1467-9280.2006.01716.x

Fazio, R. H., \& Dunton, B. C. (1997). Categorization by race: The impact of automatic and controlled components of racial prejudice. Journal of Experimental Social Psychology, 33, 451-470. doi:10.1006/ jesp.1997.1330 
Fiske, S. T., Cuddy, A. J. C., \& Glick, P. S. (2007). Universal dimensions of social cognition: Warmth and competence. Trends in Cognitive Sciences, 11, 77-83. doi:10.1016/j.tics.2006.11.005

Fiske, S. T., Cuddy, A. J. C., Glick, P. S., \& Xu, J. (2002). A model of (often mixed) stereotype content: Competence and warmth respectively follow from perceived status and competition. Journal of Personality and Social Psychology, 82, 878-902. doi:10.1037/0022-3514.82.6.878

Fitzmaurice, G. M., Laird, N. M., \& Ware, J. H. (2004). Applied longitudinal analysis. New York, NY: Wiley.

Freeman, J. B., \& Ambady, N. (2009). Motions of the hand expose the partial and parallel activation of stereotypes. Psychological Science, 20, 1183-1188. doi:10.1111/j.1467-9280.2009.02422.x

Freeman, J. B., \& Ambady, N. (2010). MouseTracker: Software for studying real-time mental processing using a computer mouse-tracking method. Behavior Research Methods, 42, 226-241. doi:10.3758/ BRM.42.1.226

Freeman, J. B., \& Ambady, N. (2011). A dynamic interactive theory of person construal. Psychological Review, 118, 247-279. doi:10.1037/ a0022327

Freeman, J. B., Ambady, N., Rule, N. O., \& Johnson, K. L. (2008). Will a category cue attract you? Motor output reveals dynamic competition across person construal. Journal of Experimental Psychology: General, 137, 673-690. doi:10.1037/a0013875

Freeman, J. B., Pauker, K., Apfelbaum, E. P., \& Ambady, N. (2010). Continuous dynamics in real-time perception of race. Journal of Experimental Social Psychology, 46, 179-185. doi:10.1016/j.jesp .2009 .10 .002

Gilbert, D. T., \& Hixon, J. G. (1991). The trouble of thinking: Activation and application of stereotypic beliefs. Journal of Personality and Social Psychology, 60, 509-517. doi:10.1037/0022-3514.60.4.509

Goff, P. A., Thomas, M. A., \& Jackson, M. C. (2008). "Ain't I a woman?" Towards an intersectional approach to person perception and groupbased harms. Sex Roles, 59, 392-403. doi:10.1007/s11199-008-9505-4

Grant, P. R., \& Holmes, J. G. (1981). The integration of implicit personality theory schemas and stereotype images. Social Psychology Quarterly, 44, 107-115. doi:10.2307/3033706

Greenwald, A. G., Nosek, B. A., \& Banaji, M. R. (2003). Understanding and using the Implicit Association Test: I. An improved scoring algorithm. Journal of Personality and Social Psychology, 85, 197-216. doi:10.1037/0022-3514.85.2.197

Heilbrun, A. B. (1976). Measurement of masculine and feminine sex role identities as independent dimensions. Journal of Consulting and Clinical Psychology, 44, 183-190. doi:10.1037/0022-006X.44.2.183

Hewstone, M. (1994). Revision and change of stereotypic beliefs. In W. Stroebe \& M. Hewstone (Eds.), European review of social psychology (Vol. 5, pp. 69-109). Chichester, England: Wiley.

Hewstone, M., \& Hamberger, J. (2000). Perceived variability and stereotype change. Journal of Experimental Social Psychology, 36, 103-124. doi:10.1006/jesp.1999.1398

Ho, C., \& Jackson, J. W. (2001). Attitudes toward Asian Americans: Theory and measurement. Journal of Applied Social Psychology, 31, 1553-1581. doi:10.1111/j.1559-1816.2001.tb02742.x

Hosmer, D. W., \& Lemeshow, S. (2000). Applied logistic regression (2nd ed.). New York, NY: Wiley. doi:10.1002/0471722146

Hugenberg, K., \& Bodenhausen, G. V. (2003). Facing prejudice: Implicit prejudice and the perception of facial threat. Psychological Science, 14, 640-643. doi:10.1046/j.0956-7976.2003.psci_1478.x

Hugenberg, K., \& Bodenhausen, G. V. (2004). Ambiguity in social categorization: The role of prejudice and facial affect in race categorization. Psychological Science, 15, 342-345. doi:10.1111/j.0956-7976 .2004.00680.x

Hutchings, P. B., \& Haddock, G. (2008). Look Black in anger: The role of implicit prejudice in the categorization and perceived emotional inten- sity of racially ambiguous faces. Journal of Experimental Social Psychology, 44, 1418-1420. doi:10.1016/j.jesp.2008.05.002

Johnson, K. L., \& Freeman, J. B. (2010). A "new look" at person construal: Seeing beyond dominance and discreteness. In E. Balcetis \& D. Lassiter (Eds.), The social psychology of visual perception (pp. 253-272). New York, NY: Psychology Press.

Johnson, K. L., \& Ghavami, N. (2011). At the crossroads of conspicuous and concealable: What race categories communicate about sexual orientation. PLoS One, 6, e18025. doi:10.1371/journal.pone.0018025

Johnson, K. L., \& Tassinary, L. G. (2007a). Compatibility of basic social perceptions determines perceived attractiveness. Proceedings of the $\mathrm{Na}$ tional Academy of Sciences, USA, 104, 5246-5251. doi:10.1073/ pnas.0608181104

Johnson, K. L., \& Tassinary, L. G. (2007b). The functional significance of the WHR in judgments of attractiveness. In V. Swami \& A. Furnham (Eds.), Body beautiful: Evolutionary and sociocultural perspectives (pp. 159-184). New York, NY: Palgrave Macmillian.

Kang, S. K., \& Chasteen, A. L. (2009). Beyond the double-jeopardy hypothesis: Assessing emotion on the faces of multiply-categorizable targets of prejudice. Journal of Experimental Social Psychology, 45, 1281-1285. doi:10.1016/j.jesp.2009.07.002

Karlins, M., Coffman, T. L., \& Walters, G. (1969). On the fading of social stereotypes: Studies in three generations of college students. Journal of Personality and Social Psychology, 13, 1-16. doi:10.1037/h0027994

Kunda, Z., Miller, D. T., \& Claire, T. (1990). Combining social concepts: The role of causal reasoning. Cognitive Science, 14, 551-577. doi: $10.1207 / \mathrm{s} 15516709 \operatorname{cog} 1404 \_3$

Kunda, Z., \& Thagard, P. (1996). Forming impressions from stereotypes, traits, and behaviors: A parallel-constraint-satisfaction theory. Psychological Review, 103, 284-308. doi:10.1037/0033-295X.103.2.284

Kurzban, R., Tooby, J., \& Cosmides, L. (2001). Can race be erased? Coalitional computation and social categorization. Proceedings of the National Academy of Sciences, USA, 98, 15387-15392. doi:10.1073/ pnas. 251541498

Levin, D. T., \& Banaji, M. R. (2006). Distortions in the perceived lightness of faces: The role of race categories. Journal of Experimental Psychology: General, 135, 501-512. doi:10.1037/0096-3445.135.4.501

Livingston, R., \& Pearce, N. (2009). The teddy bear effect: Does babyfacedness benefit Black CEOs? Psychological Science, 20, 1229-1236.

MacLin, O. H., \& Malpass, R. S. (2001). Racial categorization of faces: The ambiguous race face effect. Psychology, Public Policy, and Law, 7 98-118. doi:10.1037/1076-8971.7.1.98

MacLin, O. H., \& Malpass, R. S. (2003). The ambiguous race face illusion. Perception, 32, 249-252. doi:10.1068/p5046

Macrae, C. N., Quinn, K. A., Mason, M. F., \& Quadflieg, S. (2005) Understanding others: The face of person construal. Journal of Personality and Social Psychology, 89, 686-695. doi:10.1037/00223514.89.5.686

Martin, D., \& Macrae, C. N. (2007). A face with a cue: Exploring the inevitability of person categorization. European Journal of Social Psychology, 37, 806-816. doi:10.1002/ejsp.445

Mason, M. F., Cloutier, J., \& Macrae, C. N. (2006). On construing others: Category and stereotype activation from facial cues. Social Cognition, 24, 540-562. doi:10.1521/soco.2006.24.5.540

Matsumoto, D., \& Ekman, P. (1988). Japanese and Caucasian Facial Expressions of Emotion (JACFEE). San Francisco, CA: Author.

McKinstry, C., Dale, R., \& Spivey, M. J. (2008). Action dynamics reveal parallel competition in decision making. Psychological Science, 19, 22-24. doi:10.1111/j.1467-9280.2008.02041.x

Merritt, R. D., \& Harrison, T. W. (2006). Gender and ethnicity attributions to a gender- and ethnically-unspecified individual: Is there a "people = white male" bias? Sex Roles, 54, 787-797. doi:10.1007/s11199-0069046-7

Miller, S. L., Maner, J. K., \& Becker, D. V. (2010). Self-protective biases 
in group categorization: Threat cues shape the psychological boundary between "us" and "them." Journal of Personality and Social Psychology, 99, 62-77. doi:10.1037/a0018086

Minear, M., \& Park, D. C. (2004). A lifespan database of adult facial stimuli. Behavior Research Methods, Instruments, \& Computers, 36, 630-633. doi:10.3758/BF03206543

Park, B., Smith, J. A., \& Correll, J. (2008). "Having it all" or "doing it all”? Perceived trait attributes and behavioral obligations as a function of workload, parenthood, and gender. European Journal of Social Psychology, 38, 1156-1164. doi:10.1002/ejsp.535

Pauker, K., \& Ambady, N. (2009). Multiracial faces: The boundaries of race. Journal of Social Issues, 65, 69-86. doi:10.1111/j.15404560.2008.01588.x

Pauker, K., Rule, N. O., \& Ambady, N. (2010). Ambiguity and social perception. In E. Balcetis \& D. Lassiter (Eds.), The social psychology of visual perception (pp. 13-29). New York, NY: Psychology Press.

Pauker, K., Weisbuch, M., Ambady, N., Sommers, S. R., Adams, R. B., Jr., $\&$ Ivcevic, Z. (2009). Not so black and white: Memory for ambiguous group members. Journal of Personality and Social Psychology, 96, 795-810. doi:10.1037/a0013265

Pendry, L. F., \& Macrae, C. N. (1996). What the disinterested perceiver overlooks: Goal-directed social categorization. Personality and Social Psychology Bulletin, 22, 249-256. doi:10.1177/0146167296223003

Pinel, E. C., Long, A. E., \& Crimin, L. A. (2008). We're warmer (they're more competent): I-sharing and African-American' perceptions of the ingroup and outgroup. European Journal of Social Psychology, 38, 1184-1192. doi:10.1002/ejsp.562

Prentice, D. A., \& Carranza, E. (2002). What women and men should be, shouldn't be, are allowed to be, and don't have to be: The contents of prescriptive gender stereotypes. Psychology of Women Quarterly, 26, 269-281. doi:10.1111/1471-6402.t01-1-00066

Purdie-Vaughns, V., \& Eibach, R. P. (2008). Intersectional invisibility: The distinctive advantages and disadvantages of multiple subordinate-group identities. Sex Roles, 59, 337-391. doi:10.1007/s11199-008-9424-4

Quinn, K. A., \& Macrae, C. N. (2005). Categorizing others: The dynamics of person construal. Journal of Personality and Social Psychology, 88, 467-479. doi:10.1037/0022-3514.88.3.467

Richards, Z., \& Hewstone, M. (2001). Subtyping and subgrouping: Processes for the prevention and promotion of stereotype change. Personality and Social Psychology Review, 5, 52-73.

Rule, N. O., Ambady, N., Adams, R. B., Jr., \& Macrae, C. N. (2008). Accuracy and awareness in the perception and categorization of male sexual orientation. Journal of Personality and Social Psychology, 95, 1019-1028. doi:10.1037/a0013194

Sesko, A. K., \& Biernat, M. (2010). Prototypes of race and gender: The invisibility of Black women. Journal of Experimental Social Psychology, 46, 356-360. doi:10.1016/j.jesp.2009.10.016

Shields, S. A. (2008). Gender: An intersectionality perspective. Sex Roles, 59, 301-311. doi:10.1007/s11199-008-9501-8

Sinclair, L., \& Kunda, Z. (1999). Reactions to a black professional:
Motivated inhibition and activation of conflicting stereotypes. Journal of Personality and Social Psychology, 77, 885-904. doi:10.1037/00223514.77.5.885

Smith, E. R., \& Zárate, M. A. (1992). Exemplar-based model of social judgment. Psychological Review, 99, 3-21. doi:10.1037/0033295X.99.1.3

Spence, J. T., Helmreich, R., \& Strapp, J. (1974). The personal attributes questionnaire: A measure of sex-role stereotypes and masculinityfemininity. JSAS Catalog of Selected Documents in Psychology, 4, 43 (Ms. No. 617).

Spivey, M. J., \& Dale, R. (2006). Continuous temporal dynamics in real-time cognition. Psychological Science, 15, 207-211.

Stroessner, S. J. (1996). Social categorization by race or sex: Effects of perceived non-normalcy on response times. Social Cognition, 14, 247 276. doi:10.1521/soco.1996.14.3.247

Tajfel, H. (1969). Cognitive aspects of prejudice. Journal of Social Issues, 25, 79-97. doi:10.1111/j.1540-4560.1969.tb00620.x

Tajfel, H. (1974). Social identity and intergroup behavior. Social Science Information, 14, 65-93. doi:10.1177/053901847401300204

Tottenham, N., Tanaka, J., Leon, A. C., McCarry, T., Nurse, M., Hare, T. A., .. Nelson, C. (2009). The NimStim set of facial expressions: Judgments from untrained research participants. Psychiatry Research, 168, 242-249. doi:10.1016/j.psychres.2008.05.006

Wiggins, J. S. (1991). Agency and communion as conceptual coordinates for the understanding and measurement of interpersonal behavior. In W. Grove \& D. Cicchetti (Eds.), Thinking clearly about psychology: Essays in honor of Paul Meehl (Vol. 2, pp. 89-113). Minneapolis, MN: University of Minnesota Press.

Wojnowicz, M. T., Ferguson, M. J., Dale, R., \& Spivey, M. J. (2009). The self-organization of explicit attitudes. Psychological Science, 20, 1428 1435. doi:10.1111/j.1467-9280.2009.02448.x

Yzerbyt, V., Coull, A., \& Rocher, S. (1999). Fencing off the deviant: The role of cognitive resources in the maintenance of stereotypes. Journal of Personality and Social Psychology, 77, 449-462. doi:10.1037/00223514.77.3.449

Zárate, M. A., \& Smith, E. R. (1990). Person categorization and stereotyping. Social Cognition, 8, 161-185. doi:10.1521/soco.1990.8.2.161

Zebrowitz, L. A., Fellous, J. M., Mignault, A., \& Andreoletti, C. (2003). Trait impressions as overgeneralized responses to adaptively significant facial qualities: Evidence from connectionist modeling. Personality and Social Psychology Review, 7, 194-215. doi:10.1207/ S15327957PSPR0703_01

Zebrowitz, L. A., Kikuchi, M., \& Fellous, J. M. (2010). Facial resemblance to emotions: Group differences, impression effects, and race stereotypes. Journal of Personality and Social Psychology, 98, 175-189. doi $10.1037 / \mathrm{a} 0017990$

Received September 20, 2010

Revision received June 22, 2011

Accepted July 5, 2011 